\title{
Ultrasound Guided Nerve Root Injection in Patients with Cervical Spondylytic Radicular Pain
}

\author{
LT Choong, MS Ortho \\ Rafflesia Medical Centre, Kota Kinabalu, Sabah, Malaysia
}

\begin{abstract}
Selective cervical nerve root injection using a mixture of corticosteroid and lignocaine is a treatment option for managing cervical radiculopathic pain. The procedure is usually performed under image guided fluoroscopy or Computerized Tomograhy. Ultrasound-guided cervical nerve root block does not expose the patients and personnel to radiation. During injection, the fluid is mostly visualized in a real-time fashion. This retrospective study reviewed the effectiveness of ultrasound in guiding cervical peri-radicular injection for pain relief in patients with recalcitrant cervical radiculopathy. There were no complications reported in this series.
\end{abstract}

Key Words:

Ultrasound guided, Nerve blocks, Cervical radiculopathy

\section{INTRODUCTION}

Cervical radiculopathy is pain perceived in the upper limb caused by irritation of a cervical spinal nerve, and is caused mostly by cervical disk herniation or cervical spondylosis. Besides pain, other symptoms associated with cervical radiculopathy are numbness, paraesthesia or weakness of the muscles of the upper limb. A majority of patients who have cervical radiculopathy improve within 1 to 2 months with appropriate medical treatment, usually consisting of rest, cervical immobilization, analgesics, anti-inflammatory agents, and muscle relaxants ${ }^{1,2}$.

Selective cervical nerve root injection/blocks allow for further pain control and reduction of the use of inflammatory mediators in patients with persistent radiculopathy. In addition to being a therapeutic treatment modality, these injections also can provide specific and targeted diagnostic value at the same sitting. Many such blocks are performed in outpatient clinics with imaging guidance such as fluoroscopy or Computerized Tomography (CT). The use of ultrasound in guiding cervical nerve root block was initially described by Galiano et $a l^{3}$ in cadaveric studies in 2005 . The objective of this review is to evaluate the effectiveness of ultrasound in facilitating cervical periradicular corticosteroid injection to control pain in patients with cervical radiculopathy that is resistant to conventional medical treatment.

\section{MATERIALS AND METHODS}

A year-long retrospective review was performed during 2007-2008 on a selected group of 20 outpatients who underwent ultrasound guided selective nerve root injection for their cervical radiculopathic pain. Inclusion criteria were: persistent radicular pain after at least 4 weeks of appropriate medical therapy, a pain score of 6 to 10 on the Visual Analogue Scale and informed consent to undergo the procedure.

The diagnosis of cervical radiculopathy was established by history and physical examination findings. The root level involved was determined from the radiating pain location, the distribution of paraesthesia or motor weakness, or a combination of both.

Radiographs of the cervical spine, CT or magnetic resonance imaging (MRI) examination were not routinely performed in all patients.

\section{Technique}

The procedure was performed under ultrasound guidance by the author under sterile conditions. Patients were positioned in the lateral decubitus position. Sonography (using a Toshiba Ultrasound Scanner) of the nerve roots and the transverses processes of the cervical spine was performed to established the level of interest in the transverse plane ${ }^{4}$. The entry point for the needle insertion was marked in the long axis. The skin was then thoroughly cleansed with iodinated alcohol. Under ultrasound guided imaging, a 21-gauge spinal needle was gently pushed toward the posterior tubercle of the transverse process. Once the tip of the needle reached the posterior tubercle of the targeted vertebra, it was slowly advanced five to ten $\mathrm{mm}$ anteriorly toward the targeted nerve root. After careful aspiration to exclude blood, a mixture of one $\mathrm{ml}$ of lidocaine (2\% Xylocaine, Astra Zeneca) and one $\mathrm{ml}$ of 40mg triamcinolone acetonide (Shincort, Yung Shin Korea) was injected with a three-ml syringe.

The entire procedure, including patient positioning, lasted about 15 minutes. Immediately after the injection, the patient was asked whether the pain had diminished. If the patient did not response to the selected nerve block, another nerve block was performed at a different level. One hour later, patients were discharged and instructed to continue 


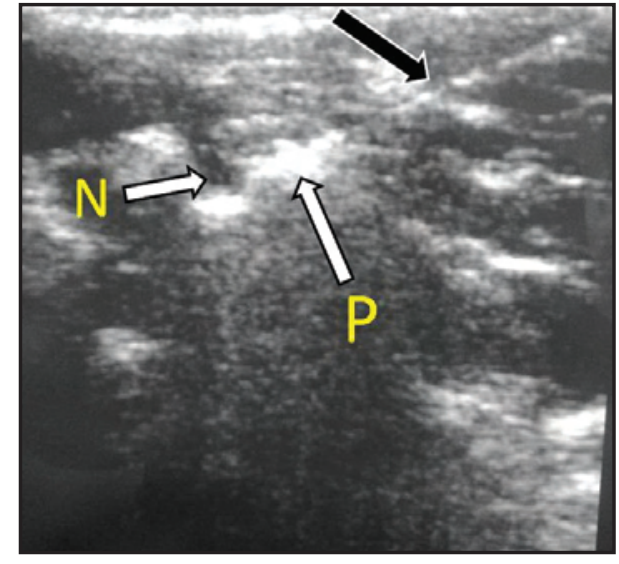

Fig. 1: Ultrasound image of the needle (black arrow pointed at white straight line) at the posterior tubercle of the transverse process of C6 (P). The nerve root is located close by $(\mathrm{N})$.

medical treatment, including wearing a cervical collar, for two weeks.

The patients were followed up at biweekly intervals for one month after the first therapeutic injection. After one month they were followed up at monthly intervals for a minimum period of three months. During the follow up, a second injection was offered to patients who claimed $50 \%$ or less pain reduction (based on the visual analogue scale).

\section{RESULTS}

There were 16 men and 4 women in the study group, with an age range from 29 to 66 years (mean 52.8 years). The average symptom duration at initial presentation was 3.8 months. Five patients presented with $\mathrm{C} 5$ nerve roots radiculopathy, 12 with C6 nerve root radiculopathy and three with C7 nerve root radiculopathy. Radicular pain relief was rapid with all patients claiming a reduction in pain immediately after the procedure injection (local anaesthetic effect). The presumed root level of cervical radiculopathy was accurate in 18 out of 20 patients, two patients did not respond to the selected nerve root level involvement, and were then reinjected at another reselected level to control the pain. At the two-week follow up, three patients received a second injection. At the fourweek follow up, one patient received a third injection. There were no patients who required more than four injections within a three-month period.

\section{Pain Score}

The patients were followed for a period of three months following the first treatment. Patients scored the intensity of radicular pain on a VAS ranging from 0 (no pain) to 10 (maximal intensity). Based on the pain score before the procedure, percentages of pain relief assessed at two weeks and three months after periradicular injection were calculated. These percentages of pain relief were classified as "excellent" when the pain was completely resolved or had diminished by $75 \%$ or more, "good" for a diminution of $50 \%-74 \%$, "fair" for a diminution of $25 \%-49 \%$, or "poor" for a diminution of less than $25 \%$.

Before the procedure, the VAS range was from 6 to 10 with a mean of 8.2. At two weeks post-injection, the mean VAS was 3.8 and at 3 months follow-up the mean VAS was 2.2. Two weeks after the periradicular injection, $60 \%$ of the patients reported excellent to good pain relief and had their medication reduced or discontinued. The mean pain scores decreased from 8.1 points to 2.2 points (mean decrease of 5.9). Radicular pain relief was fair or poor for $40 \%$ of the patients, with a mean pain score that decreased from 8.4 points to 6.1 points (mean decrease of 2.3). All of these patients continued their medical treatment two weeks after the procedure.

At the three months follow up, an overall good or excellent result was observed in 16 patients $(80 \%)$. They were either pain-free or their pain was minimal and did not require constant analgesic medication. A fair result was seen in two patients and two patients had a poor result. Three patients' required continued daily medication for pain control and one patient underwent surgery.

\section{DISCUSSION}

Cervical radiculopathy improves with nonsurgical treatment in a majority of patients. Although the use of cervical nerve root blocks have not been proven to change the natural history of cervical radiculopathy ${ }^{5}$, patients with severe radicular pain can have their pain controlled effectively with selective cervical nerve root steroid injections.

Berger et $a l^{6}$ and Cyteval et $a l^{7}$ studied CT-guided foraminal injections and reported effective long-term pain relief in $60 \%$ of their patients with cervical radiculopathy. Slipman et $a l^{8}$ and Valee $e t a l^{9}$ investigated fluoroscopically guided cervical nerve root block in their series of patients with cervical spondylitic radicular pain. An overall good or excellent result was observed in $60 \%$ and $53 \%$ of their patients respectively. Neither the duration of symptoms before infiltration nor the intensity of pain or cause of the radiculalgia were found to be predictive of radicular pain relief ${ }^{7,9}$.

Of note, there have been catastrophic complications reported during CT or fluoroscopically guided transforaminal cervical nerve root injections. Described injuries include brain infarct, spinal cord infarct and death ${ }^{5,10}$. During the procedure, the intima of the vertebral artery can be punctured and injured leading to dissection ${ }^{10}$. Proposed mechanisms to explain injury to more proximal central nervous system structures include embolic microvascular occlusion from particulate corticosteroids inadvertently injected into the vertebral intracranial circulation. Similarly it has been 
postulated that occlusion of the spinal radicular artery can occur when particulate corticosteroids are injected intravascularly, thus jeopardizing the blood supply to the cervical spinal cord resulting in spinal cord infarct.

In the current study, ultrasound guided cervical nerve root injection was effective in providing rapid pain relief in $60 \%$ of patients, with the pain relief lasting a minimum of two weeks. At three months follow up, $80 \%$ of the patients continued with excellent to good results.

There were no complications noted in this series of twenty patients. The injection was deposited lateral to the cervical foramen at the level of the transverse processes. This improves the safety level without compromising the efficacy of pain relief. Schellhas et al ${ }^{11}$ also reported no complications in his series of 4612 patients using an extraforaminal approach during fluoroscopically guided selective cervical nerve root blocks.
Unlike fluoroscopy and CT, ultrasound does not expose patients and personnel to radiation. There is no requirement to perform the procedure in a radiation shielded room and neither is there a need to wear X ray protective apparel and goggles. Imaging can be performed continuously. The sonographer watches the needle at all time during advancement. The fluid injected is mostly visualized in a real-time fashion. The vertebral artery is also visualized using Doppler sonography, so the risk of intravascular injection of local anaesthetics or injury to the vessel is avoided. The procedure can be performed alone without the need for any radiographer or nurse assistance.

\section{CONCLUSION}

Ultrasound is a good alternative to fluoroscopy and CT scan to guide cervical nerve root injection for patients with severe cervical radiculopathic pain. In addition to its cost effectiveness, the procedure is relatively safe as the vertebral artery can be visualized and avoided. 


\section{REFERENCES}

1. Ellenberg MR, Honet JC, Treanor WJ. Cervical radiculopathy. Arch Phys Med Rehabil 1994; 75: 342-352.

2. Saal JS, Saal JA, Yurth EF. Nonoperative management of herniated cervical intervertebral disc with radiculopathy. Spine 1996; 21: $1877-83$.

3. Galiano K, Obwegeser AA, Bodner G, Freund MC, Gruber H, Maurer H, et al. Ultrasound-guided periradicular injections in the middle to lower cervical spine: an imaging study of a new approach. Reg Anesth Pain Med 2005; 30(4): 391-6.

4. Martinoli C, Bianchi S, Santacroce E, Pugliese F, Graif M, Derchi LE. Brachial Plexus Sonography: A Technique for Assessing the Root Level. AJR Am J Roentgenol 2002;179(3): 699-702.

5. Santiago-Palma J, Vallejo R, Kornick C, Barna S. Are Cervical Nerve Root Blocks "Safe and Effective"? AJNR Am J Neuroradiol 2005; 26(9): 2434-5.

6. Berger O, Dousset V, Delmer O, Pointillart V, Vital JM, Caille JM. Evaluation of the efficacy of foraminal infusions of corticosteroids guided by computed tomography in the treatment of radicular pain by foraminal injection. J Radiol 1999; 80: 917-25.

7. Cyteval C, Thomas E, Decoux E, Sarrabere MP, Cottin A, Blotman F, et al. Cervical Radiculopathy: Open Study on Percutaneous Periradicular Foraminal Steroid Infiltration Performed under CT Control in 30 Patients. Am J Neuroradiol 2004; 25(3): 441-5.

8. Slipman CW, Lipetz JS, Jackson HB, Rogers DP, Vresilovic EJ. Therapeutic selective nerve root block in the nonsurgical treatment of atraumatic cervical spondylotic radicular pain: a retrospective analysis with independent clinical review. Arch Phys Med Rehabil 2000; 81: 741-6.

9. Vallée JN, Feydy A, Carlier RY, Mutschler C, Mompoint D and Vallée CA. Chronic Cervical Radiculopathy: Lateral-Approach Periradicular Corticosteroid Injection. Radiology 2001; 218: 886-92.

10. Wallace MA, Fukui MB, Williams RL, Ku A, Baghai P. Complications of Cervical Selective Nerve Root Blocks Performed with Fluoroscopic Guidance. Am J Neuroradiol 2007; 188(5): 1218-21.

11. Schellhas KP, Pollei SR, Johnson BA, Golden MJ, Eklund JA, Pobiel RS. Selective Cervical Nerve Root Blockade: Experience with a Safe and Reliable Technique Using an Anterolateral Approach for Needle Placement. Am J Neuroradiol 2007; 28(10): 1909-14. 